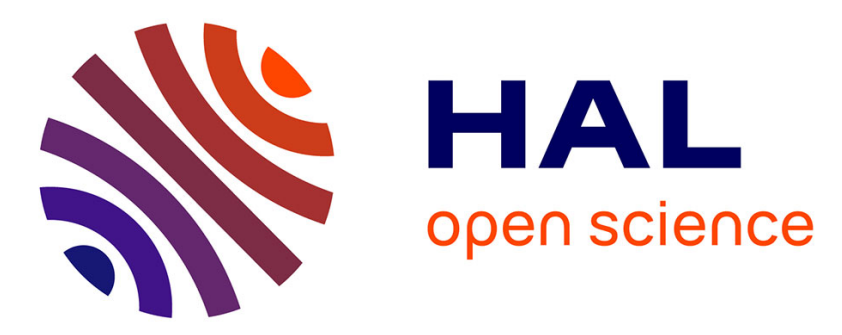

\title{
TiO 2 supported Ru catalysts for the hydrogenation of succinic acid: influence of the support
}

Magdalena Brzezinska, Johannes Niemeier, Yannik Louven, Nicolas Keller, Regina Palkovits, Agnieszka Ruppert

\section{- To cite this version:}

Magdalena Brzezinska, Johannes Niemeier, Yannik Louven, Nicolas Keller, Regina Palkovits, et al.. TiO 2 supported Ru catalysts for the hydrogenation of succinic acid: influence of the support. Catalysis Science \& Technology, 2020, 10 (20), pp.6860-6869. 10.1039/D0CY01446J . hal-03004536

\section{HAL Id: hal-03004536 https://hal.science/hal-03004536}

Submitted on 16 Dec 2020

HAL is a multi-disciplinary open access archive for the deposit and dissemination of scientific research documents, whether they are published or not. The documents may come from teaching and research institutions in France or abroad, or from public or private research centers.
L'archive ouverte pluridisciplinaire HAL, est destinée au dépôt et à la diffusion de documents scientifiques de niveau recherche, publiés ou non, émanant des établissements d'enseignement et de recherche français ou étrangers, des laboratoires publics ou privés. 


\section{$\mathrm{TiO}_{2}$ supported $\mathrm{Ru}$ catalysts for the hydrogenation of succinic acid: influence of the support}

Received 00th January 20xx, Accepted 00th January 20xx DOI: $10.1039 / x 0 \times x 00000 x$

\author{
Magdalena Brzezinska, ${ }^{a}$ Johannes Niemeier, ${ }^{\mathrm{b}}$ Yannik Louven, ${ }^{\mathrm{b}}$ Nicolas Keller, ${ }^{\mathrm{c}}$ Regina Palkovits ${ }^{\mathrm{b}}$ and \\ Agnieszka M. Ruppert*a
}

\begin{abstract}
Succinic acid is a valuable biomass-derived platform molecule, which can be further catalytically converted into many industrially relevant molecules such as $\gamma$-butyrolactone, 1,4-butanediol or tetrahydrofuran. The influence of the support nature on both the activity of $\mathrm{Ru} / \mathrm{TiO}_{2}$ catalysts and the selectivity pattern in the hydrogenation of succinic acid was investigated, with focus on the metal-support interaction, the crystallographic structure of the $\mathrm{TiO}_{2}$ support and the supported Ru nanoparticle size features. We showed that the catalyst activity was related to both the Ru particle size and the metal support interaction, those features being induced by the presence of the rutile phase within the $\mathrm{TiO}_{2}$ support and by the preparation method of the supported Ru particles. The rutile phase not only favors the formation of small Ru particles but also promotes stronger metal-support interaction compared with the anatase polymorph. Strong interactions between metal and support can also be formed via thermal reduction in contrast to low-temperature direct chemical reduction. Interestingly, a low temperature solar photon-assisted synthesis method facilitates very high succinic acid conversion, by enabling the stabilization of $1.8 \mathrm{~nm}$ small-size Ru nanoparticles in the absence of any rutile phase within the $\mathrm{TiO}_{2}$ support.
\end{abstract}

\section{Introduction}

Succinic acid (SA) is one of the most important platform building blocks which can be applied in future biorefinery schemes. It has numerous applications and can notably be used as a "green" and non-toxic source of C4 chemicals such as $\gamma^{-}$ butyrolactone (GBL), 1,4-butanediol (BDO) and tetrahydrofuran (THF) (Scheme 1). GBL is a high value chemical with an annual production reaching $250000 \mathrm{t}$, that is widely used as a solvent as well as a starting material for the synthesis of $\mathrm{N}$ methylpyrrolidone and of other pyrrolidones. BDO is used in the production of various polymers and of elastic fibres, such as polyterephthalates and polyurethanes, while THF is mainly used as a green solvent and substrate in the production of polytetramethylene ether glycol and of other polymer-based materials (e.g. Spandex). ${ }^{1}$

Whereas succinic acid has traditionally been produced from petroleum-based feedstock, nowadays it can however be efficiently obtained via a more environmentally friendly pathway, namely through processes based on the fermentation of biomass-derived sugars. ${ }^{2}$ In those processes, succinic acid is obtained dissolved in aqueous phase. To avoid the energy-

\footnotetext{
a. Institute of General and Ecological Chemistry, Faculty of Chemistry, tódź University of Technology, ul. Żeromskiego 116, 90-924 Łódź, Poland *e-mail: agnieszka.ruppert@p.lodz.pl; Fax: +48426313128; Tel: +48426313106 b. Institut für Technische und Makromolekulare Chemie, RWTH Aachen University, Worringerweg 2, 52074 Aachen, Germany

c. Institut de Chimie et Procédés pour l'Energie, l'Environnement et la Santé, ICPEES, CNRS, University of Strasbourg, 25 rue Becquerel, 67087 Strasbourg, France Electronic Supplementary Information (ESI) available: XRD and TPR characterization, illustration of the bonded CO molecules in FTIR. See DOI: 10.1039/x0xx00000x
}

intense separation from water and facilitate integration along the chemical value chain, the search for heterogeneous catalysts which are stable in water is highly desired.

In the last decade, different catalysts, mostly based on metals like $\mathrm{Pd}, \mathrm{Ru}, \mathrm{Pt}$, Re or $\mathrm{Cu}$, were investigated in this process, ${ }^{3,4}$ and several studies concentrated on Pd-based catalysts. Zhang et al. identified the Pd dispersion as a key factor responsible for high selectivity towards GBL (98\%) obtained on $\mathrm{Pd} / \mathrm{AlOOH}$ catalysts. They combined theoretical investigation and experimental data concluding that single $\mathrm{Pd}$ atoms are responsible for the high catalytic performance. ${ }^{5}$ Uniform, highly dispersed Pd nanoclusters supported on amino-functionalized silica spheres were also considered as active species responsible for the high GBL yield in the work of You et al. The role of the support was mainly related to the improved dispersion which enhanced the activity. ${ }^{6}$ Similarly, Song's group highlighted dispersion as a key-factor allowing to reach a high selectivity in the case of mesoporous composite Pd-based catalysts. ${ }^{7}$

Despite the significant focus on other metals, ruthenium was recognized in several works as the most active metal in this reaction. Its high activity was, however, often associated with a poor selectivity towards GBL. By comparing the activity of different metals (Pd, Pt, Rh, Ru) supported on carbon, Luque et al. have found that, although the $\mathrm{Ru} / \mathrm{C}$ catalyst led to the highest conversion, THF was the main product instead of the highly valuable GBL. ${ }^{3}$

The selectivity towards GBL obtained with Ru catalysts can be significantly improved when doping by Re. The synergetic effect obtained through the Re-Ru association allowed to increase the selectivity to $\mathrm{GBL}$, and the catalyst strongly outperformed the analogous $\mathrm{Pd}$-Re bimetallic system that 
requires a much longer reaction time for achieving comparable selectivity. ${ }^{8}$ A similar effect can also be obtained through the addition of Co to the Ru catalyst, and the existence of new Co$\mathrm{Ru}$ interactions allowed to significantly decrease the time necessary to achieve full succinic acid conversion from $7 \mathrm{~h}$ to 2 $\mathrm{h}$ for a reaction conducted in a dioxane-rich water solvent $(15: 1)$ at $250^{\circ} \mathrm{C}$ under 103.5 bar of $\mathrm{H}_{2} .{ }^{9}$

Despite a significant literature input devoted to the influence of metal dopants, there is only limited information concerning the influence of the support nature and properties on the catalytic activity in the hydrogenation of SA.

A direct effect of the support was reported by Chung et al. for mesoporous structured materials. In comparison to the MCM support, the incorporation of smaller Pd clusters within the SBA channels was proposed to directly result from the intrinsic structure of the SBA material, and to be responsible for the activity boost and the formation of cyclic products like GBL and THF.$^{10}$ The Corma's group investigated the influence of both the support nature and the metal nanoparticle size on the catalytic activity in biomass-derived dicarboxylic acid hydrogenation. The authors reported that $\mathrm{Ru} / \mathrm{TiO}_{2}$ showed better catalytic performance than $\mathrm{Ru} / \mathrm{C}$ or $\mathrm{Ru} / \mathrm{CeO}_{2}$ catalysts. Furthermore, the metal loading was optimized for the applied reaction conditions, a catalyst with a lower Ru content $(0.64 \%)$ being more active in the carboxylic acid hydrogenation than those with higher metal contents (up to $5 \%$ ). ${ }^{11}$

Later on, the group of Pinel demonstrated that both the titania support nature and the preparation method impacted on the activity of $\mathrm{Pd} / \mathrm{TiO}_{2}$ catalysts. The authors showed that the deposition-precipitation method provided the most active catalysts independently of the titania support used. The highest conversion was observed for anatase-supported samples and was ascribed mainly to the good dispersion of the metal, whereas far lower conversions were obtained using a mixed phase anatase/rutile $\mathrm{TiO}_{2}-\mathrm{P} 25$ support. In contrast, no difference was observed in terms of selectivity pattern. Succinic acid was transformed firstly to GBL, which was further hydrogenated to BDO and THF, but only after reaching almost full conversion of SA. ${ }^{12}$ In another study, the same group evaluated two different titania materials as supports for Pd-Re catalysts, and suggested the enhanced dispersion of the metals as the key-factor responsible for the improved activity obtained for the anatase supported Pd-Re catalysts. ${ }^{8,13,14}$

We recently showed however that not only the metal dispersion was responsible for reaching high levels of conversion on $\mathrm{TiO}_{2}$ supported $\mathrm{Ru}$ catalysts. In the case of the hydrogenation of levulinic acid to $\gamma$-valerolactone in water as a solvent, the co-existence of both anatase and rutile polymorphs within the support was crucial. In addition, the interaction of the $\mathrm{Ru}$ nanoparticles to the anatase and rutile phases was reported to be of different character, and was proposed to significantly impact the catalytic performance. ${ }^{15}$

In the current work, we studied the influence of the titania support nature on both the activity of $\mathrm{Ru} / \mathrm{TiO}_{2}$ catalysts and the selectivity pattern in the hydrogenation of succinic acid. We especially focused on the metal-support interaction, the crystallographic structure of the $\mathrm{TiO}_{2}$ support and the mean $\mathrm{Ru}$ particle size, as well as on the influence of the catalyst preparation method on the its performance.

\section{Experimental}

\section{$\mathrm{TiO}_{2}$ supports}

Different $\mathrm{TiO}_{2}$ materials were used as supports. Rutileanatase mixed-phase Aeroxide ${ }^{\circledR} \mathrm{TiO}_{2}$ P25 and P90 were delivered by Evonik-Degussa, and are further denoted as P25 and P90, respectively. Pure anatase-phase Hombikat UV100 was delivered by Sachtleben Chemie $\mathrm{GmbH}$, and used as-is or after a calcination in static air at $500^{\circ} \mathrm{C}$ for $3 \mathrm{~h}$ (labeled as UV100 and UV100C, respectively).

Pure anatase-phase $\mathrm{TiO}_{2}$, labeled as Anatase-P, was prepared via a sol-gel method in basic conditions with a final calcination at $500^{\circ} \mathrm{C}$ in static air, using a titanium tetraisopropoxide ethanolic solution as precursor and ammonia as a $\mathrm{pH}$-adjusting agent, as detailed in ${ }^{16}$.

Pure rutile-phase $\mathrm{TiO}_{2}$, further denoted as Rutile, was synthesized as described in the literature 17 , through the controlled aging at room temperature of an anatase hydrosol derived from the hydrolysis of titanium isopropoxide in a hydrochloric acid aqueous solution in the presence of polyethyleneglycol porogen. After drying, the sample was submitted to a final calcination in flowing air $(20 \mathrm{ml} / \mathrm{min})$ at $500^{\circ} \mathrm{C}$ for $2 \mathrm{~h}$ (heating rate of $2^{\circ} \mathrm{C} / \mathrm{min}$ ).

\section{Catalyst preparation}

$\mathrm{Ru} / \mathrm{TiO}_{2}$ catalysts with $1 \mathrm{wt} . \%$ metal loading were prepared via different impregnation methods. P25-, P90-, UV100-, UV100C- and rutile-supported catalysts were prepared by wet impregnation of the supports with $\mathrm{Ru}(\mathrm{acac})_{3}$ (Sigma-Aldrich, 97\%) methanolic solutions. After aging and evaporation of the solvent excess, the solid was dried at $120^{\circ} \mathrm{C}$ for $2 \mathrm{~h}$, calcined in static air at $200^{\circ} \mathrm{C}$ for $2 \mathrm{~h}$ and finally submitted to a reductive treatment at the same temperature in hydrogen flow $(60$ $\mathrm{ml} / \mathrm{min}$ ) for $1 \mathrm{~h}$.

$\mathrm{Ru} / \mathrm{TiO}_{2}$ catalyst was also prepared using the UV100 support through the chemical reduction of ruthenium(III) nitrosyl nitrate (Adrich, 99.99\%) using $\mathrm{NaBH}_{4}$ (Sigma-Aldrich, 99\%) as a reductive agent. The aqueous suspension of the titania support was stirred for $1 \mathrm{~h}$ in presence of $\mathrm{Ru}(\mathrm{NO})\left(\mathrm{NO}_{3}\right)_{3}$, before a threefold molar excess of $\mathrm{NaBH}_{4}$ was added. After stirring for 15 $\mathrm{min}$, the catalyst was further washed with deionized water and dried at $120^{\circ} \mathrm{C}$ for $2 \mathrm{~h}$. This sample was further labeled as UV100CR.

Furthermore, in the case of the Anatase-P support, a $\mathrm{Ru} / \mathrm{TiO}_{2}$ catalyst was prepared via a solar light-photoassisted synthesis method using $\mathrm{Ru}(\mathrm{acac})_{3}$ as precursor as described in the literature 18,19 . It involved the controlled irradiation with simulated solar light for $3 \mathrm{~h}$ of a water-methanol $\mathrm{TiO}_{2}$ suspension in the presence of the Ru precursor, by taking advantage of the solar light-induced properties developed by the $\mathrm{TiO}_{2}$ surface for reducing the Ru precursor adsorbed at the support surface into metallic Ru. After filtration and washing 
with deionized water, the catalyst was dried at $100^{\circ} \mathrm{C}$ before being used as-is without any final reductive treatment.

\section{Material characterization}

XRD measurements were carried out on a D8 Advance Bruker diffractometer in a $\theta / \theta$ mode and using the $K \alpha 1$ radiation of $\mathrm{Cu}$ at $1.5406 \AA$. The mean $\mathrm{TiO}_{2}$ crystallite size, i.e. the average size of the coherently diffracting domains, was determined from the Scherrer equation with the usual assumption of spherical crystallites. The $\mathrm{TiO}_{2}$ materials are characterized by their percentage of rutile phase obtained on pure rutile and on $\mathrm{P} 25$ containing $20 \%$ of rutile phase, the phase composition corresponding to the composition within the crystallized $\mathrm{TiO}_{2}$ phases (without considering the content of amorphous $\mathrm{TiO}_{2}$ ).

Surface area and porosimetry measurements were carried out on ASAP2010 Micromeritics using $\mathrm{N}_{2}$ as adsorbant at $-196^{\circ} \mathrm{C}$, with a prior outgassing at $200^{\circ} \mathrm{C}$ for $3 \mathrm{~h}$ in order to desorb the impurities or moisture. BET specific surface area was calculated from the nitrogen adsorption isotherm and the micropore surface area was derived using the t-plot method.

TEM measurements were conducted to measure particle size. TEM JEOL 2010 and JEOL 2100 microscopes operating at $200 \mathrm{kV}$ equipped with an energy dispersive X-ray detector were used. The average Ru nanoparticle size was defined as usually :

$$
d=\frac{\sum_{i=1}^{N} n_{i} d_{i}^{3}}{\sum_{i=1}^{N} n_{i} d_{i}^{2}}
$$

$n_{i}$ and $d_{i}$ being the number and the diameter of the Ru particles in each particle fraction, respectively, and $N$ the total number of particles measured (over 300 whatever the sample).

TPR measurements were carried out on an AMI1 system from Altamira Instruments, equipped with a thermal conductivity detector, and were performed for investigating the catalyst reducibility. Before the measurement, the calcined catalysts were pre-treated with an $\mathrm{O}_{2} / \mathrm{Ar}(2: 98 \mathrm{v} / \mathrm{v})$ flow for 30 $\min$ at $200^{\circ} \mathrm{C}$ with heating rate of $10^{\circ} \mathrm{C} / \mathrm{min}$, and further submitted to $\mathrm{a}_{2} / \operatorname{Ar}(5: 95 \mathrm{v} / \mathrm{v})$ flow at a weight hourly space velocity of $0.161 \mathrm{~h}^{-1}$.

$\mathrm{CO}$ adsorption/desorption measurements were carried out with a Nicolet 6700 FTIR spectrometer equipped with MCT detector made by Thermo Scientific, using a transmission cell. All spectra were recorded in a wavenumber range of 2300-1700 $\mathrm{cm}^{-1}$, with a scan number of 64 and a spectral resolution set at $4 \mathrm{~cm}^{-1}$. Before the measurement, the samples were first reduced following the same procedure used to prepare the catalysts. After reduction, the samples were cooled down to $40^{\circ} \mathrm{C}$ in $\mathrm{Ar}$, before the $\mathrm{CO}$ sorption was performed for $20 \mathrm{~min}$ and the spectra were collected every $5 \mathrm{~min}$. The $\mathrm{CO}$ desorption occurred through a purge with pure Ar for $20 \mathrm{~min}$, and the spectra were collected every $2 \mathrm{~min}$. Gas flow was set at 20 $\mathrm{ml} / \mathrm{min}$

\section{Catalytic activity tests}

In a typical succinic acid hydrogenation experiment, $1 \mathrm{~g}$ of succinic acid, $0.3 \mathrm{~g}$ of a catalyst and $10 \mathrm{ml}$ of water were combined in a $50 \mathrm{ml}$ stainless steel autoclave, equipped with a teflon insert. The reactor was pressurized with hydrogen to 50 bar and the reaction was performed at $180^{\circ} \mathrm{C}$ for $18 \mathrm{~h}$ at a stirring speed of $1000 \mathrm{rpm}$. The reaction conditions were selected for achieving conversion levels allowing valid comparison of the catalyst performances, in agreement with the previous literature reports. ${ }^{11,14,20}$ The reactor was further cooled down with ice-water and the remaining pressure was released. The obtained reaction mixture was then centrifuged to separate the catalyst from the solution. The solution was subsequently sampled using ethanol as a solvent and $\mathrm{n}$-hexanol as an internal standard, and the products were further analysed on an HP-5890 GC instrument equipped with flame ionization detector and a WAX column.

Considering GBL, THF and $\mathrm{BDO}$ as the only detected products from the SA conversion in those conditions, in agreement with the well-established literature reports 20,21 , the conversion, selectivity and yield patterns used for characterizing the catalyst behavior were calculated as follows:

$$
\begin{gathered}
\text { Conversion }=\frac{\sum n_{\text {prod }}}{n_{S A_{i}}} \cdot 100 \% \\
\text { Selectivity }=\frac{n_{\text {prod }}}{\sum n_{\text {prod }}} \cdot 100 \% \\
\text { Yield }=\frac{n_{\text {prod }}}{n_{S A_{i}}} \cdot 100 \%
\end{gathered}
$$

$n_{S A i}$ being the number of moles of initial SA molecules, and $n_{\text {prod }}$ being the number of moles of a given product within the reaction mixture.

Additionally, the activity was defined here as the number of succinic acid molecules converted per number of Ru atoms per hour, as follows:

$$
\text { Activity }=\frac{\sum n_{\text {prod }}}{n_{R u} \cdot t}
$$

$t$ being time and $n_{R u}$ being the number of Ru atoms.

\section{Results and discussion}

\section{Characterization of the titania support materials}

The main physico-chemical properties of the titania supports used are listed in Table 1 and their XRD patterns are shown in Figure S1. The materials differ in terms of phase composition, from pure anatase to pure rutile phase, as well as with regard to the specific surface area. It has to be mentioned that the phase composition corresponds to the composition within the crystalline $\mathrm{TiO}_{2}$ phases, so that eg. a support for which rutile is the only crystallized phase is referred to a pure rutile support. The composition depends on the synthesis process and with the thermal stability of titania as the rutile 


\begin{tabular}{|c|c|c|c|c|c|c|}
\hline & \multicolumn{6}{|c|}{$\mathrm{TiO}_{2}$ supports } \\
\hline & P25 & P90 & UV100 & UV100C & Anatase-P & Rutile \\
\hline Composition [\%] $]^{\mathrm{a}, \mathrm{b}}$ & $\begin{array}{l}R: 20 \\
A: 80\end{array}$ & $\begin{array}{l}\mathrm{R}: 10 \\
\mathrm{~A}: 90\end{array}$ & A: 100 & A: 100 & A: 100 & R: 100 \\
\hline Amorphous phase [\%] ${ }^{c}$ & 7 & 29 & 26 & 30 & 39 & 34 \\
\hline Average crystallite size $[\mathrm{nm}]^{\mathrm{d}}$ & $\begin{array}{l}R: 32 \\
A: 22\end{array}$ & $\begin{array}{l}\text { R: } 23 \\
\text { A: } 13\end{array}$ & 9 & 14 & 24 & 17 \\
\hline $\begin{array}{l}\text { BET surface area (microporous } \\
\text { content) }\left[\mathrm{m}^{2} \mathrm{~g}^{-1}\right]\end{array}$ & $55(0)$ & $90(0)$ & $330(243)$ & $80(0)$ & $27(0)$ & $26(0)$ \\
\hline Pore volume $\left[\mathrm{cm}^{3} \mathrm{~g}^{-1}\right]$ & 0.12 & 0.24 & 0.22 & 0.32 & 0.14 & 0.19 \\
\hline
\end{tabular}

\footnotetext{
a the phase composition corresponds to the composition within the crystallized $\mathrm{TiO}_{2}$ phases (without considering the content of amorphous $\mathrm{TiO}_{2}$ )

${ }^{\mathrm{b}} \mathrm{A}$ and $\mathrm{R}$ represent the anatase and rutile content in the $\mathrm{TiO}_{2}$ phase composition, respectively

${ }^{\mathrm{c}}$ determined by using the method developed in $\operatorname{ref}^{22}$

${ }^{\mathrm{d}}$ determined by applying the Scherrer equation to the (101) and (110) peaks of anatase and rutile, at $25.7^{\circ}$ and $27.5^{\circ}$, respectively.
}

phase is the most stable form. The presence of an amorphous phase does not appear to be a key parameter in obtaining high surface area samples. The specific surface area is globally related to the $\mathrm{TiO}_{2}$ crystallite size for samples possessing anatase as the unique or main crystallized phase, with a surface area increasing from 26 to $330 \mathrm{~m}^{2} / \mathrm{g}$ when the anatase mean crystallite size decreases from 22 to $9 \mathrm{~nm}$. All the supports were free of micropores, except the $\mathrm{TiO}_{2}$ UV100 material, for which the micropores contributed to a large extent to its high specific surface area of $330 \mathrm{~m}^{2} / \mathrm{g}$. Those micropores are considered to result from the dense agglomeration of small-size nanocrystallites. Calcining the high surface area $\mathrm{TiO}_{2}$ anatase material reduced the microporous content of the support and allowed preparing a pure anatase support with a relatively high surface area compared to the analogous anatase support prepared via the sol-gel synthesis, i.e. $80 \mathrm{vs.} 27 \mathrm{~m}^{2} / g$. Due to the use of a porogen during the sol-gel synthesis, the pure rutile $\mathrm{TiO}_{2}$ support maintained a moderate surface area of $26 \mathrm{~m}^{2} / \mathrm{g}$ and resisted the structure collapse during the high temperature calcination at $500^{\circ} \mathrm{C}^{17}$

\section{Characterization of the catalysts}

TEM studies were performed in order to characterize the Ru particle size of the catalysts (Figure 1). There were used for deriving the Ru particle size distributions and the corresponding mean $\mathrm{Ru}$ particle sizes. Figure 2 depicts the influence of the rutile phase content within the $\mathrm{TiO}_{2}$ support on the mean $\mathrm{Ru}$ particle size. In the case of the standard wet impregnation method, the presence of the $\mathrm{TiO}_{2}$ rutile phase within the support was a key factor for obtaining small Ru particles with narrow size distribution, and the mean nanoparticle size decreased with the increase in the rutile content, the mean size profile reaching a plateau at ca. $2.1 \mathrm{~nm}$ for $\mathrm{Ru}$ catalysts containing rutile-rich $\mathrm{TiO}_{2}$ supports. Indeed, similar small average particle sizes of $2.2 \mathrm{~nm}$ and $2.1 \mathrm{~nm}$ were obtained on pure rutile and on P25 containing $20 \%$ of rutile phase, while a slightly weaker dispersion - with an average Ru particle size of $2.9 \mathrm{~nm}$ - was obtained on the P90 support that contains a lower content of rutile phase at $10 \%$. In addition, our previous works showed that the Ru nanoparticles were mainly located on the rutile crystallites when both polymorph phases coexisted within the support. The presence of the rutile phase stimulates the formation of small metal particles on its surface during the preparation step as a consequence of the crystallographic phase similarity of titania and $\mathrm{RuO}_{2} \cdot{ }^{15}$ This was further confirmed by Hernandez-Meija et al. who obtained large Ru agglomerates on anatase $\mathrm{TiO}_{2}{ }^{23}$ In contrast, on the pure anatase high surface area UV100 support, the formation of rather large and nonhomogeneous $\mathrm{Ru}$ particles and aggregates did not allow any average particle size to be calculated, while a large average particle size of $10 \mathrm{~nm}$ was obtained in the case of the catalyst supported on medium surface area anatase $\mathrm{TiO}_{2}$ (UV100C). 

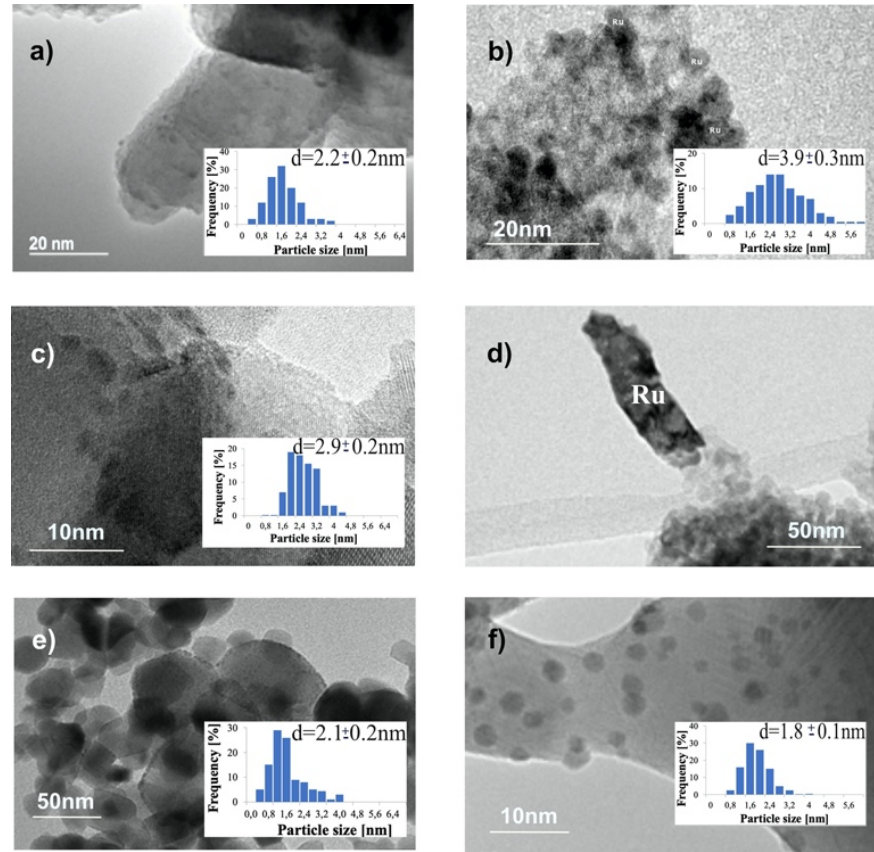

Figure 1. TEM images of $\mathrm{Ru} / \mathrm{TiO}_{2}$ catalysts prepared via wet impregnation, with the corresponding Ru particle size distribution and the mean Ru particle size, for a) rutile, b) UV100 (via chemical reduction), c) P90, d) UV100, e) P25 and f) $\mathrm{TiO}_{2}$ anatase (photoassisted method). No size distribution could be obtained for Ru/UV100 sample using wet impregnation.

The impossibility to obtain a high and homogeneous dispersion of Ru particles on the high specific surface area pure anatase $\mathrm{TiO}_{2}$ (UV100) highlighted the importance of using alternative preparation methods in order to obtain small size Ru particles on pure anatase supports. First, the use of $\mathrm{NaBH}_{4}$ as a room temperature chemical reductant allowed to prepare $\mathrm{Ru}$ nanoparticles with a mean particle size of $4 \mathrm{~nm}$. Further, the implementation of a one-step solar light photon-assisted synthesis method allowed to prepare highly dispersed Ru nanoparticles in the case of the Ru/Anatase-P material. The redox photoactivity developed by the anatase $\mathrm{TiO}_{2}$ support under solar light gave way to a mean Ru particle size of $1.8 \mathrm{~nm}$. The photo-assisted synthesis facilitated the reduction of the adsorbed metallic Ru precursor to metallic nanoparticles with a controlled growth at the support surface, overcoming the need of any further reductive treatment at elevated temperatures. ${ }^{19}$

FTIR spectra of adsorbed CO recorded for the Ru catalysts show the presence of several bands at 1950, 1990-2000, 20602070,2130 and $2170 \mathrm{~cm}^{-1}$. In the case of supported Ru catalysts, there is an ongoing discussion on the interpretation of the FTIR spectra and on band assignment. ${ }^{24-30}$ However, those bands could be attributed to bridge-bonded $\mathrm{CO}$ at $1950 \mathrm{~cm}^{-1}$, linearly bonded CO on steps at $1990-2000 \mathrm{~cm}^{-1}$, linearly bonded CO on faces at $2060-2070 \mathrm{~cm}^{-1}, 30$ multicarbonyl species on partially oxidized Ru crystallites at $2130 \mathrm{~cm}^{-1}$, 31 and $\mathrm{CO}$ adsorbed on the titania surface at $2170 \mathrm{~cm}^{-1}$ (illustration of the differently bonded $\mathrm{CO}$ is provided in Fig. S2). ${ }^{24}$ The band corresponding to bridge-bonded $\mathrm{CO}$ was only observed for the high surface area anatase sample, probably due to the existence of very large $\mathrm{Ru}$ crystallites accessible for $\mathrm{CO}$, and coexisted with the low- intensity band assigned to the linearly adsorbed CO. The lowest band intensities were observed in the case of the Ru/UV100 catalyst, what may suggest a location of a part of the Ru nanoparticles in the support micropores, with a resulting lower accessibility for $\mathrm{CO}$ molecules. Indeed, the removal of the microporosity by calcination of the support further led to the disappearance of the band assigned to bridge-bonded $\mathrm{CO}$, while the total intensity of the bands corresponding to linearly bonded $\mathrm{CO}$ increased. The increase in the rutile phase content in the samples is connected with the increase of the band intensity and with the decrease of the ruthenium particle size.

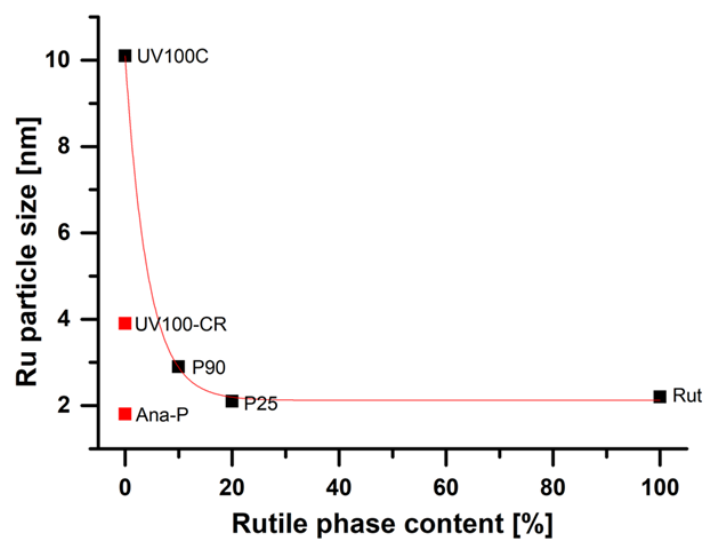

Figure 2. Influence of the rutile phase content within the $\mathrm{TiO}_{2}$ support on the mean $\mathrm{Ru}$ nanoparticle size. The graph does not take into account the Ru/UV100 catalyst, since no valuable mean $\mathrm{Ru}$ particle size could be measured for this support using wet impregnation.

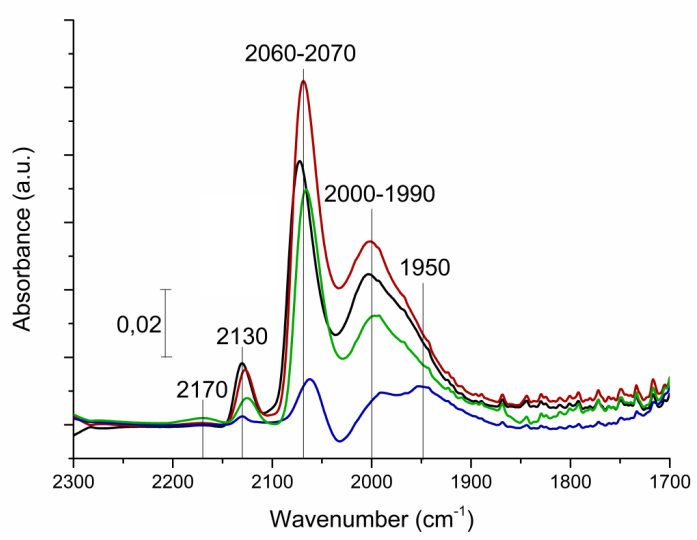

Figure 3. FTIR absorbance spectra of adsorbed $\mathrm{CO}$ obtained for the Ru catalysts on the rutile (red); $\mathrm{TiO}_{2} \mathrm{P} 25$ (black); $\mathrm{TiO}_{2}$ UV100C (green) and $\mathrm{TiO}_{2}$ UV100 (blue).

Figure 4a shows the influence of the rutile phase content in the $\mathrm{TiO}_{2}$ support on the maximum temperature of complete reduction of the supported phase. It can be observed that the maximum temperature of complete reduction first strongly increases with the increase in the rutile phase content until it reaches a $20 \%$ content, and further increases only moderately 
a)

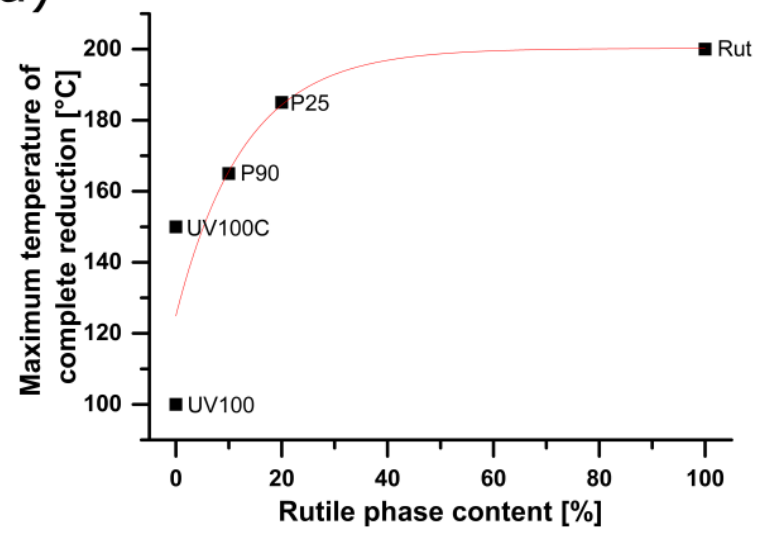

b)

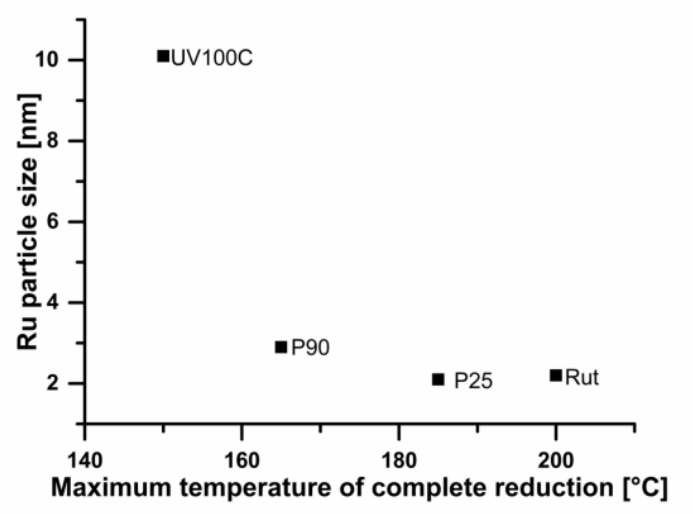

Figure 4 a) Influence of the rutile phase content in the $\mathrm{TiO}_{2}$ support and b) influence of the mean Ru particle size on the maximum temperature of complete reduction, for catalysts prepared by wet impregnation. The graphs do not consider samples prepared by direct chemical reduction or via the photon-assisted synthesis method, for which no reduction peak is observed (a), and also specifically for (b) the Ru/UV100 catalyst prepared by wet impregnation, since no mean particle size could be measured.

for a higher rutile content. The lowest value of $100^{\circ} \mathrm{C}$ is observed for the catalyst supported on high surface area anatase (UV100), while this temperature further increases to $150^{\circ} \mathrm{C}, 165-185^{\circ} \mathrm{C}$ and finally $200^{\circ} \mathrm{C}$ for medium surface area anatase (UV100C), mixed-phase supports containing rutile, and the pure rutile support, respectively. It may suggest that the rutile phase interacts more strongly with the ruthenium particles, so that a higher temperature is needed for complete reduction. This indicates that the crystalline phase of the $\mathrm{TiO}_{2}$ support strongly and directly impacts the full reduction of the supported Ru species, and consequently the strength of the interaction with the support.

The group of Crossley showed that the presence of rutile in the support stabilizes the Ru particles and consequently prevents the sintering phenomena. ${ }^{32}$ The group of Weckhuysen have further reported the absence of any sintering when Ru was supported on a mixed phase as well as on pure rutile supports, while Ru sintering was observed on pure anatase phase. ${ }^{33}$ Further, Sassoye et al. indicated that the migration of $\mathrm{RuO}_{2}$ can be observed from the anatase to the rutile phase when the $\mathrm{TiO}_{2}$ support contains both polymorphs. ${ }^{34}$ This confirmed the existence of weaker interactions of the supported Ru species with the anatase phase than with the rutile phase.

Taking into account that the rutile content in the support may also influence on the Ru crystallite size, in Figure $4 \mathrm{~b}$ we show the relationship between the mean $\mathrm{Ru}$ particle size and the maximum temperature of complete reduction that characterizes the strength of the $\mathrm{Ru}-\mathrm{TiO}_{2}$ interactions. Generally, stronger interactions are related to the presence of smaller particles. However, the Ru particle size is not a predominant factor affecting the temperature of complete reduction of the supported phase, except for the UV100C-based catalyst. Indeed, the complete reduction temperature varies from $160^{\circ} \mathrm{C}$ up to $200^{\circ} \mathrm{C}$ in the case of the P90, P25 and rutile supports, although they exhibit a rather similar Ru nanoparticle mean size.

\section{Catalytic activity}

Table 2 and Figure 5 show the performances of the $\mathrm{Ru} / \mathrm{TiO}_{2}$ catalysts in the succinic acid hydrogenation reaction. Catalysts supported on different titanias varying in terms of preparation method, crystalline phase content and specific surface areas were examined.

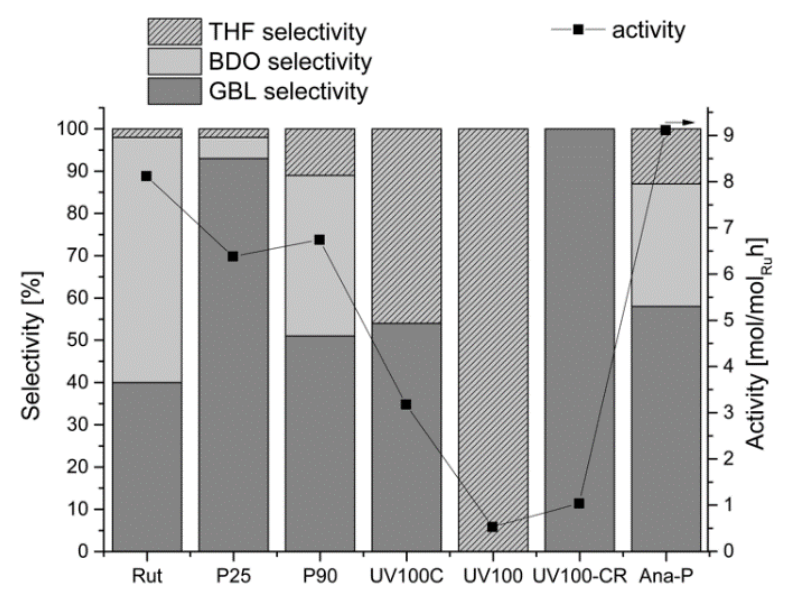

Figure 5. Catalytic efficiency of the Ru catalysts in terms of activity and selectivity to GBL, THF and BDO. Reaction time of $18 \mathrm{~h}$ at $180^{\circ} \mathrm{C}$ under 50 bar $\mathrm{H}_{2}$.

High succinic acid conversion was achieved using pure rutile as support for Ru catalyst, with an activity of $8.1 \mathrm{~mol} / \mathrm{mol}_{\mathrm{Ru}} \cdot \mathrm{h}$, and selectivities to GBL and BDO of $40 \%$ and $58 \%$, respectively. The presence of anatase within the mixed-phase supports was detrimental for the catalytic activity, which dropped down to 6.4-6.7 mol/ $\mathrm{mol}_{\mathrm{Ru}} \cdot \mathrm{h}$ on both Ru/P25 and Ru/P90 catalysts, and also lower conversions of $40-43 \%$ were achieved. However, mainly GBL was observed on Ru/P25, with a selectivity of $93 \%$, while the reaction was less selective on $\mathrm{Ru} / \mathrm{P} 90$, with a broad 
Table 2 Catalytic efficiency of the Ru catalysts with $1 \mathrm{wt} . \%$ metal loading in terms of activity, SA conversion as well as selectivity to GBL, THF and BDO. Reaction time of $18 \mathrm{~h}$ at $180^{\circ} \mathrm{C}$ under 50 bar $\mathrm{H}_{2}$.

\begin{tabular}{|c|c|c|c|c|c|}
\hline Ru catalyst & Activity $\left[\mathrm{mol} / \mathrm{mol}_{\mathrm{Ru}} \cdot \mathrm{h}\right]$ & SA conversion [\%] & GBL selectivity [\%] & THF selectivity [\%] & BDO selectivity [\%] \\
\hline Rutile & 8.1 & 51 & 40 & 2 & 58 \\
\hline P25 & 6.4 & 40 & 93 & 2 & 5 \\
\hline $\mathrm{P} 25^{*}$ & 6.7 & 43 & 67 & 6 & 27 \\
\hline P90 & 6.7 & 43 & 51 & 11 & 38 \\
\hline UV100C & 3.2 & 20 & 54 & 46 & 0 \\
\hline UV100 & 0.5 & 3 & 0 & 100 & 0 \\
\hline UV100-CR & 1.0 & 7 & 100 & 0 & 0 \\
\hline Anatase-P & 9.1 & 58 & 58 & 13 & 29 \\
\hline
\end{tabular}

* result obtained after reaction at $180^{\circ} \mathrm{C}$ and under 80 bar $\mathrm{H}_{2}$

product distribution of $51 \%$ for GBL, $38 \%$ for BDO and a relatively large THF contribution of $11 \%$.

In the case of the Ru catalysts prepared on pure anatase by wet impregnation, far lower activities and SA conversions were obtained, whether the micropore content of the support has been suppressed by calcination or not. The reaction pathway proceeds towards THF through the transformation of the GBL intermediate, and a THF selectivity of $46 \%$ at a SA conversion of $20 \%$ (activity of $3.2 \mathrm{~mol} / \mathrm{molRu} \cdot \mathrm{h}$ ) was observed with UV100C. Using high surface area UV100 with a high microporous content as a support, a further drop in activity to $0.5 \mathrm{~mol} / \mathrm{molRu} \cdot \mathrm{h}$ was observed, with a full THF selectivity.

\section{Discussion}

We investigated the activity of $\mathrm{TiO}_{2}$ supported Ru catalysts in the hydrogenation of succinic acid, and several key factors with a significant influence on the process have been identified.

\section{Metal-support interaction}

Firstly, the activity was strongly influenced by the strength and kind of interaction between the $\mathrm{TiO}_{2}$ support and the $\mathrm{Ru}$ nanoparticles in the catalysts prepared via classical wet impregnation. TPR characterization shown in Fig. S3 illustrates that the stronger the interaction between the Ru nanoparticles and the $\mathrm{TiO}_{2}$ support is, the higher is the maximum temperature of complete reduction of the supported $\mathrm{Ru}$ phase. It can consequently be concluded from Fig. 6 that the stronger are the interactions between metallic $\mathrm{Ru}$ and the support when a thermal treatment under $\mathrm{H}_{2}$ was applied (classical wet impregnation method), the higher is the catalytic activity.

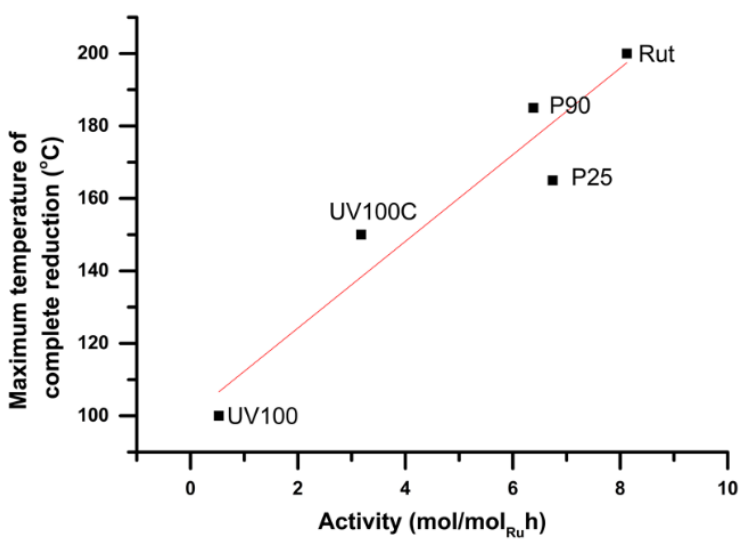

Figure 6. Influence of the maximum temperature of complete reduction of the supported Ru phase on the activity of the catalyst prepared via the wet impregnation method. No reduction peaks are indeed observed for samples prepared by direct chemical reduction or through the solar photon-assisted synthesis method.

\section{$\mathrm{TiO}_{2}$ crystalline structure}

The $\mathrm{TiO}_{2}$ crystalline structure has been previously pointed out as a key factor influencing the interaction with the support when a thermal treatment under $\mathrm{H}_{2}$ was applied (Fig. 4). Consequently, the relationship depicting the influence of the rutile phase content of the support on the activity of the catalysts was illustrated in Fig. 7a. This revealed that the presence of the rutile phase was strongly beneficial to the activity for the catalysts prepared via impregnation. Indeed, the catalysts prepared on pure anatase (UV100 and UV100C) showed the lowest activity, that strongly increased with increasing the rutile content, even in small amounts (10-20\%). Increasing further the rutile content leads only to a moderate activity gain, with ca. $6.5 \mathrm{~mol} / \mathrm{molRu} \cdot \mathrm{h}$ for both P25- and P90supported Ru catalysts, and $8.1 \mathrm{~mol} / \mathrm{molRu} \cdot \mathrm{h}$ for the pure rutilebased catalyst. The slightly lower activity of the P25 catalyst may be connected with the formation of electron-deficient Ru species which can be formed on the anatase/rutile junction. 
a)

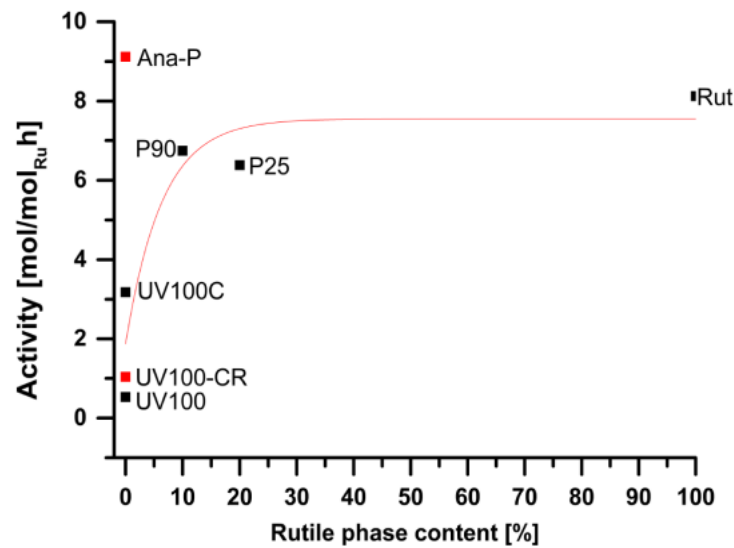

b)

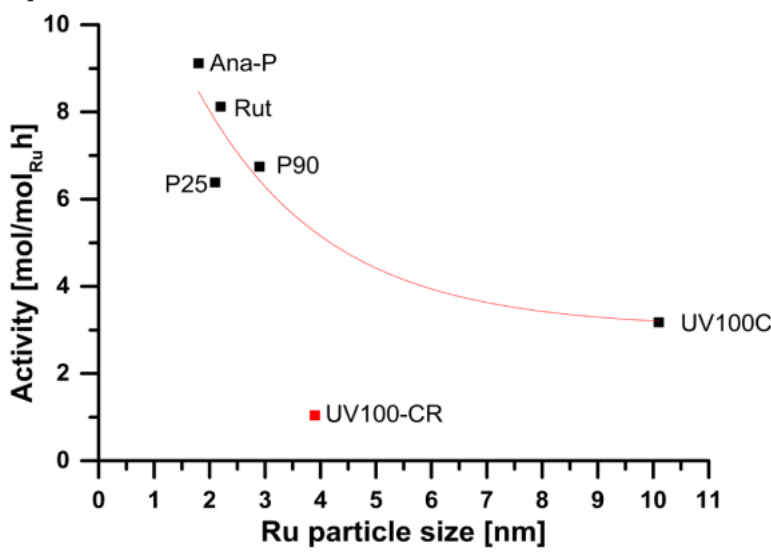

Figure 7. a) influence of the rutile phase content within the $\mathrm{TiO}_{2}$ support and b) influence of the Ru particle size on the catalyst activity in $\mathrm{SA}$ hydrogenation. The graph does not take into account the Ru/UV100 catalyst, since no valuable mean Ru particle size could be measured for this support using the wet impregnation method

This phenomena may weaken the adsorption strength of the substrate and change the adsorption of molecules at the surface, resulting in a lower activity of the catalyst. ${ }^{35}$

The beneficial input of the rutile polymorph on the activity of Ru catalysts was highlighted by Hernandez-Meija et al. for the xylose hydrogenation, with $98 \%$ yield to xylitol vs. $10 \%$ on pure anatase. ${ }^{23} \mathrm{Kim}$ et al. reported that the presence of rutile increased the catalyst activity in $\mathrm{CO}_{2}$ methanation, thanks to a higher $\mathrm{Ru}$ dispersion originating from the $\mathrm{RuO}_{2}$ migration towards the rutile phase and the subsequent stabilization of Ru particles by epitaxy. ${ }^{34}$ The group of Weckhuysen also evidenced that the Ru catalyst stability depended on the crystallographic nature of the titania support, strong sintering being observed on pure anatase, while an irreversible reduction of the anatase support caused by strong levulinic acid adsorption induced the SMSI effect. ${ }^{33}$

\section{Ru nanoparticle size}

Not only the rutile phase content is an important factor determining the catalytic activity, but also the Ru particle size. In Figure 7b, we illustrate that indeed, the highest activity (9.1 $\mathrm{mol} / \mathrm{mol}_{\mathrm{Ru}} \cdot \mathrm{h}$ ) was obtained for the catalyst with the smallest mean Ru particle size $(1.8 \mathrm{~nm})$, i.e. the Ru/Ana-P. The activity globally decreased with increasing the mean Ru crystallite size. The lowest activity of $3.2 \mathrm{~mol} / \mathrm{mol}_{\mathrm{Ru}} \cdot \mathrm{h}$ was achieved for the catalyst with the largest mean particle size of $10 \mathrm{~nm}$, i.e. $\mathrm{Ru} / \mathrm{V} 100 \mathrm{C}$. This is in agreement with the group of Besson who correlated the catalyst activity in the succinic acid hydrogenation with the particle size of $\mathrm{Pd}$ dispersed on $\mathrm{TiO}_{2}{ }^{12}$ Also the group of Corma identified that the particle size plays an important role in the hydrogenation of functionalized carboxylic acids with $\mathrm{Ru} / \mathrm{TiO}_{2}$ catalysts, for which no other factors were taken into consideration. ${ }^{11}$ In contrast, for catalysts supported on different oxides, other factors are dominant and such a relationship can be observed. In addition, Liu et al. reported that the crystallographic structure of the $\mathrm{TiO}_{2}$ phase induces a chemical shift in the binding energy of metallic Pt species interacting with the $\mathrm{TiO}_{2}$ surface, consequently with a clear influence on the catalyst activity in the selective oxidation of benzyl alcohol. ${ }^{36}$

A closer look reveals that both P25- and P90-supported Ru catalysts have almost similar activities, while they differ in terms of mean Ru particle size ( $2.1 \mathrm{~nm}$ vs. $2.9 \mathrm{~nm})$, indicating that the particle size is not the only factor affecting the activity. Also, a negligible activity was observed for the catalyst prepared via the room temperature chemical reduction with $\mathrm{NaBH}_{4}$, despite an intermediate mean Ru particle size of $3.9 \mathrm{~nm}$, suggesting that the absence of any reductive thermal treatment was detrimental to the activity, probably due to the impossibility to create proper interaction with the support. Interestingly, although here the catalyst was not submitted to any reductive thermal treatment and the support did not contain any rutile phase, the highest activity was observed for the Ru catalyst prepared via room-temperature solar light photon-assisted synthesis (Ana-P). This can be explained by the room temperature charge-driven mechanism of the photon-assisted method that does not require the presence of any rutile phase for stabilizing size-controlled $\mathrm{Ru}$ nanoparticles at the $\mathrm{TiO}_{2}$ surface. ${ }^{16,19}$ Further, we also suggest that the photogenerated electron and hole charges are subsequently transferred to the $\mathrm{Ru}-\mathrm{TiO}_{2}$ interface during the $\mathrm{Ru}$ nanocluster growth and the formation of the metallic particles, favoring the establishment of the necessary interaction between the Ru species and the $\mathrm{TiO}_{2}$ support.

We cannot rule out that the differences observed in $\mathrm{Ru}$ nanoparticle sizes might affect the electronic character of the catalysts, especially for the very small sizes. This might be considered as an additional factor contributing to the effect of the Ru nanoparticle size on the behavior of the catalysts.

\section{Product yields in SA hydrogenation}

In order to understand the relationship between the yield to the main products and the catalyst properties, Figure 8 relates the catalytic activity with the yield to GBL and BDO. The GBL yield generally increases with the activity increase, and its value 
a)

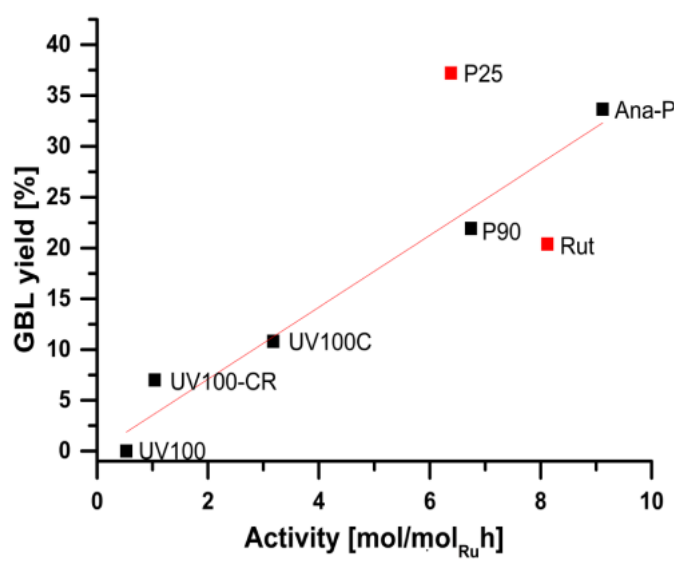

b)

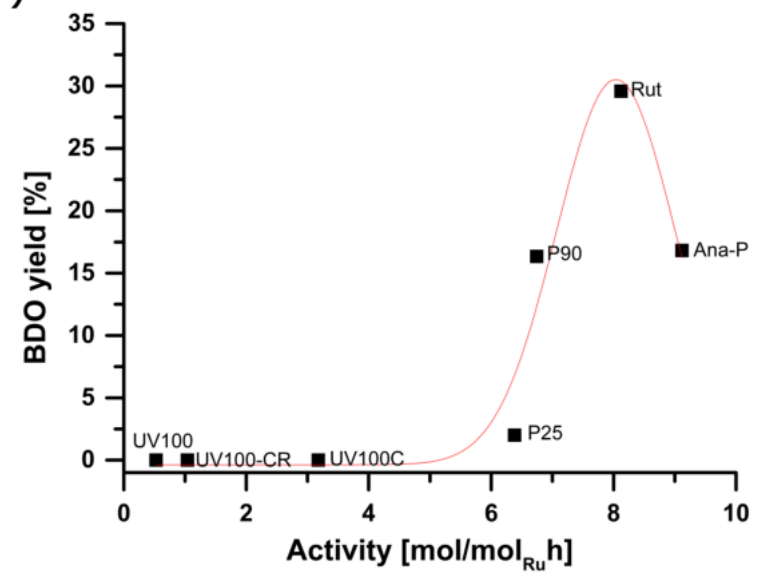

Figure 8. Influence of the activity of the catalyst on a) the GBL yield and b) the BDO yield in the SA hydrogenation.

of $37 \%$ was obtained for the Ru/P25 catalyst, while almost the same yield of $34 \%$ was achieved using the most active catalyst, prepared via the photoassisted method on the sol-gel anatase. A similar trend was noted by Ly et al. on the Re-Pd/TiO 2 catalyst, for which an increase in the GBL concentration was observed with increasing the SA conversion until full conversion was obtained; afterwards, GBL was further converted mainly into BDO with a negligible amount of side products. ${ }^{37} \mathrm{Di}$ et al. also indicated a clear relationship between $S A$ and GBL concentrations, SA being firstly converted into GBL, and further into overhydrogenated products after full SA conversion. ${ }^{38}$ The authors showed that the Ru addition is beneficial for the $\mathrm{Re} / \mathrm{C}$ catalyst activity, and that the Re-Ru interaction is pushing the reaction towards the BDO formation.

In the case of the BDO yield, a volcano-shaped pattern can be seen as a function of the catalyst activity. No BDO was observed for the catalysts supported on anatase reduced in $\mathrm{H}_{2}$ flow or with $\mathrm{NaBH}_{4}$, while a maximum yield of $30 \%$ was achieved for the catalyst supported on pure rutile. Interestingly, the catalyst supported on anatase prepared via the photoassisted method showed a certain yield to BDO (17\%).

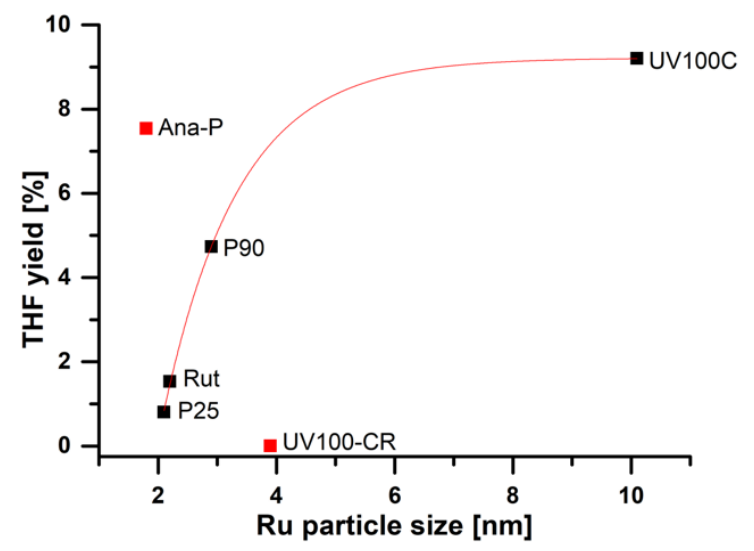

Figure 9. Influence of the mean Ru nanoparticle size on the THF yield. The graph does not include the Ru/UV100 catalyst, since no valuable mean Ru particle size could be measured for this support using wet impregnation.
As far as the THF yield was concerned, no dependence on the catalyst activity was observed. In contrast, a clear relationship could be drawn between the mean Ru nanoparticle size and the THF yield in the case of the catalysts prepared via the standard wet impregnation method (Figure 9), while no clear trend was observed for both GBL and BDO yield (not reported). Interestingly, the THF yield significantly dropped with the decrease in the mean Ru crystallite size, from $9 \%$ on the $\mathrm{Ru} / \mathrm{UV} 100 \mathrm{C}$ catalyst with a large average Ru particle size of 10 $\mathrm{nm}$, down to ca. $1 \%$ for the catalysts with the average $\mathrm{Ru}$ particle size of about $2 \mathrm{~nm}$, i,e those with $\mathrm{TiO}_{2} \mathrm{P} 25$ and pure rutile $\mathrm{TiO}_{2}$ supports. While this trend was well visible for the samples that were submitted to the final thermal treatment in order to obtain metallic Ru nanoparticles, the two other samples (for which no thermal treatment was applied) did not follow this trend. Indeed, a THF yield of $8 \%$ (i.e. close to that obtained using UV100C with large Ru crystallites) was achieved on the Ru/Anatase-P catalyst prepared via the photon-assisted synthesis crystallites, which had a small mean Ru particle size of $1.8 \mathrm{~nm}$. In contrast, the catalyst prepared by chemical reduction with $\mathrm{NaBH}_{4}$ displayed inversely a very low THF yield, while it exhibited a moderate (intermediate) mean Ru particle size of $3.9 \mathrm{~nm}$.

To summarize, we showed that the behavior of $\mathrm{Ru} / \mathrm{TiO}_{2}$ catalysts depends on both the Ru particle size and the metalsupport interaction. Those features are induced by the presence of different crystallographic phases in the support and by the preparation method. The rutile phase in the support favors the presence of small metallic Ru particles. This induces different interactions between the supported metal and the respective $\mathrm{TiO}_{2}$ phases, the $\mathrm{Ru}-\mathrm{TiO}_{2}$ interaction being reported to be stronger for rutile than for anatase. ${ }^{37}$ Stronger metal-support interaction can be also induced by using a thermal reduction method, in comparison to the low-temperature direct chemical reduction, while the solar photon-assisted method is a way to stabilize small-size Ru nanoparticles in the absence of any rutile phase within the support. 


\section{Conclusions}

By studying the influence of the titania support phase composition on both the activity of $\mathrm{Ru} / \mathrm{TiO}_{2}$ catalysts and their selectivity pattern in the hydrogenation of succinic acid, we showed that the metal-support interaction and the supported $\mathrm{Ru}$ nanoparticle size are the key factors driving the catalyst performances. Both features were induced by the presence of the rutile polymorph as well as by the preparation method used for supporting the Ru nanoparticles. Using thermal reduction in hydrogen requires the presence of the rutile phase within the support for synthesizing small-size Ru nanoparticles, the rutile phase inducing stronger metal-support interaction in comparison to the anatase counterpart, while the thermal reduction is necessary for obtaining proper ruthenium-support interactions. The low-temperature solar photon-assisted synthesis method proved to be a way to completely get rid of the presence of the rutile phase in the support, while allowing the stabilization of small size $1.8 \mathrm{~nm}$ Ru nanoparticles, and consequently facilitating very high succinic acid conversion.

\section{Conflicts of interest}

There are no conflicts to declare.

\section{References}

1 C. Delhomme, D. Weuster-Botz and E. Kuhn, Green Chem., 2009, 11, 13

2 I. Bechthold, K. Bretz, S. Kabasci, R. Kopitzky and A. Sringer, Chem. Eng. Technol., 2008, 31, 647

3 R. Luque, J. H. Clark, K. Yoshida and P. L. Gai, Chem. Commun., 2009, 5305

4 S. Varadarajan and D. J. Miller, Biotechnol. Prog., 1999, 15, 845

5 C. Zhang, L. Chen, H. Cheng, X. Zhu and Z. Qi, Catal. Today, 2016, 276, 55

6 C. You, C. Zhang, L. Chen and Z. Qi, Appl. Organomet. Chem., 2015, 653

7 U. G. Hong, J. Lee, S. Hwang and I. K. Song, Catal. Letters, 2011, 141, 332

8 D. P. Minh, M. Besson, C. Pinel, P. Fuertes and C. Petitjean, Top. Catal., 2010, 53, 1270

9 R. M. Deshpande, V. V. Buwa, C. V. Rode, R. V. Chaudhari and P. L. Mills, Catal. Commun., 2002, 3, 269

10 S.-H. Chung, Y.-M. Park, M.-S. Kim and K.-Y. Lee, Catal. Today, 2012, 185, 205

11 A. Primo, P. Concepcion and A. Corma, Chem. Commun., 2011, 47,3613

12 B. Tapin, F. Epron, C. Especel, B. K. Ly, C. Pinel and M. Besson, ACS Catal., 2013, 3, 2327

13 B. K. Ly, D. P. Minh, C. Pinel, M. Besson, B. Tapin, F. Epron and C. Especel, Top. Catal., 2012, 55, 466
14 L. Corbel-Demailly, B.-K. Ly, D.-P. Ming, B. Tapin, C. Especel, F. Epron, A. Cabiac, E. Guillon, M. Besson and C. Pinel, ChemSusChem, 2013, 6, 2388

15 A. M. Ruppert, J. Grams, M. Jędrzejczyk, J. MatrasMichalska, N. Keller, K. Ostojska and P. Sautet, ChemSusChem, 2015, 8, 1538

16 J. Wojciechowska, M. Jędrzejczyk, J. Grams, N. Keller and A. M. Ruppert, ChemSusChem, 2018, 12, 639

17 F. Bosc, A. Ayral, N. Keller and V. Keller, Appl. Catal. B, 2007, 69, 133

18 J. Wojciechowska, E. Gitzhofer, J. Grams, A. M. Ruppert and N. Keller, Materials, 2018, 11, 2329

19 J. Wojciechowska, E. Gitzhofer, J. Grams, A. M. Ruppert and N. Keller, Catal. Today, 2018, 326, 8

20 K. Hyuk, K. Ung, G. Hong, Y. Bang, J. Ho, C. Jeong, K. Kim, J. Kwon, L. Seung, J. Han and I. K. Song, Appl. Catal. A: Gen., 2015, 490, 153

21 K. Hyuk, K. Ung, G. Hong, J. Oh, J. Ji, H. Song, Y. Bang, J. Ho, C. Seung, J. Han and I. K. Song, J. Mol. Catal. A-Chem., 2014, 395, 234

22 L. Cano-Casanova, A. Amoros-Perez, M. Ouzzine, M. A. LilloRodenas and M. C. Roman-Martinez, Appl. Catal. BEnviron., 2018, 220, 645

23 C. Hernandez-Meija, E. S. Gnanakumar, A. Olivos-Suarez, J. Gascon, H. Greer, W. Zhou, G. Rothenberg and N. R. Shiju, Catal. Sci. Technol., 2016, 6, 577

24 K. Hadjiivanov, J.-C. Lavalley, J. Lamotte, F. Mauge, J. SaintJust and M. Che, J. Catal., 1998, 176, 415

25 P. Panagiotopoulou, D. I. Kondarides and X. E. Verykios, J. Phys. Chem. C, 2011, 115, 1220

26 A. M. Abdel-Mageed, D. Widmann, S. E. Olesen, I. Chorkendorff, J. Biskupek and R. J. Behm, ACS Catal., 2015, 5, 6753

27 V. Mazzieri, F. Coloma-Pascual, A. Arcoya, P. C. L'Argentiere and N. S. Figoli, Appl. Surf. Sci., 2003, 210, 222

28 S. Scire, C. Crisafulli, R. Maggiore, S. Minico and S. Galvagno, Catal. Lett., 1998, 51, 41

29 C. Elmasides and D. I. Kondarides, J. Phys. Chem. B, 1999, 103, 5227

30 E. Guglielminotti and G. C. Bond, J. Chem. Soc. Faraday Trans., 1990. 86, 979

31 J. L. Robbins, J. Catal., 1989, 115, 120

32 T. Omotoso, S. Boonyasuwata and S.P. Crossley, Catal. Sci. Technol., 2014, 6, 645.

33 F. Liu, J. Ftouni, P. C. A. Bruijnincx and B. M. Weckhuysen, ChemCatChem, 2019, 11, 2079

34 A. Kim, D. P. Debecker, F. Devred, V. Dubois, C. Sanchez and C. Sassoye, Appl. Catal. B-Environ., 2018, 220, 615

35 G. Zhou, R. Dou, H. Bi, S. Xie, Y. Pei, K. Fan, M. Qiao, B. Sun and B. Zong, J. Catal., 2015, 332, 119 
36 J. Liu, S. Zou, L. Lu, H. Zhao, L. Xiao and J. Fan, Catal. Commun., 2017, 99, 6

37 B. K. Ly, B. Tapin, F. Epron, C. Pinel, C. Especel and M. Besson, Catal. Today, 2019.

38 X. Di, C. Li, B. Zhang, J. Qi, W. Li, D. Su and C. Liang, Ind. Eng. Chem. Res., 2017, 56, 4672 